\title{
Quantitative Subcellular Localization of Calmodulin-Dependent Phosphatase in Chick Forebrain
}

\author{
Frank A. Anthony, Martin A. Winkler, Harold H. Edwards, and Wai Yiu Cheung \\ Department of Biochemistry, St. Jude Children's Research Hospital, Memphis, Tennessee 38101
}

\begin{abstract}
Using a radioimmunoassay, we have measured the level of calmodulin-dependent phosphatase (calcineurin) in various subcellular fractions from chick forebrain. Our results revealed high levels of the enzyme in the cytoplasm and microsomes. A considerable amount was also observed in synaptosomes, where it was found exclusively in the synaptoplasm, comprising $0.32 \%$ of the total synaptoplasmic protein. Immunocytochemical localization of the phosphatase in isolated synaptosomes supported the biochemical finding. Phosphatase was not detected in nuclei, myelin, synaptic vesicles, and mitochondria. These results suggest that myelin basic protein and histone $H_{1}$, widely used in biochemical characterization studies of the phosphatase, may not be physiological substrates, and that the cytoplasm, microsomes, and synaptoplasm may prove to be useful sources for the identification of physiological substrates.
\end{abstract}

Calcium plays an important role in many cellular functions, including such diverse processes as cell division and neurotransmitter release (Campbell, 1983); many of these functions are believed to be mediated through calcium-modulated proteins (Cheung, 1980; Kretsinger, 1980; Van Eldik et al., 1982). One of the best-characterized calcium-modulated proteins is calmodulin (Klee and Vanaman, 1982; Cheung, 1984; Babu et al, 1985), which regulates the activities of many enzymes, including several protein kinases and at least one protein phosphatase.

Calmodulin-dependent phosphatase, also termed calcineurin, is a heterodimer consisting of 2 subunits. Subunit $\mathrm{A}\left(M_{\mathrm{r}} 60 \mathrm{kDa}\right)$ possesses the catalytic site (Winkler et al., 1984) and binds calmodulin (Klee et al., 1979; Sharma et al., 1979); and subunit B $\left(M_{\mathrm{r}} 19 \mathrm{kDa}\right)$ resembles calmodulin (Aitken et al., 1984), binds calcium (Klee et al., 1979), and regulates the activity of subunit A (Merat et al., 1985). The N-terminus of subunit B is blocked by myristic acid (Aitken et al., 1982), a posttranslational modification shared by several transformed gene products (Marchildon et al., 1984; Sefton and Hunter, 1984; Kamps et al., 1985 ) and the catalytic subunit of cAMP-dependent protein kinase (Carr et al., 1982).

Calmodulin-dependent phosphatase catalyzes the dephosphorylation of phosphoserine, phosphothreonine, and phos-

\footnotetext{
Received Apr. 16, 1987; revised Sept. 18, 1987; accepted Sept. 29, 1987.

We are grateful to Dr. Dennis Merat for supplying phosphatase, Dr. Yu-Yan Yeh for rat oligodendrocytes, Dr. William Walker for goat anti-rabbit immunoglobulin $F_{r}$ sera, and Drs. Luis Pezzi and Nigel G. F. Cooper for helpful discussions and suggestions. We thank Patricia $A$. Suttle for editing assistance and manuscript preparation, and Donna Davis for electron microscopy. F.A.A. is the recipient of National Research Service Award CA09346.

Correspondence should be addressed to $W$. Y. Cheung at the above address. Copyright (C) 1988 Society for Neuroscience $0270-6474 / 88 / 041245-09 \$ 02.00 / 0$
}

photyrosine residues in proteins (Pallen and Wang, 1985; Pallen et al., 1985; Chan et al., 1986; Tallant and Cheung, 1986) and the dephosphorylation of several nonprotein substrates (Pallen and Wang, 1983; King and Huang, 1984; Li, 1984; Anthony ct al., 1986). However, no in vivo substrates have yet been identified.

The phosphatase has been detected in many tissues (Wallace et al., 1980; Klumpp et al., 1983; Stewart et al., 1983; Tallant and Wallace, 1985); brain is a particularly rich source (Wallace et al., 1980). Immunocytochemical localization in mouse brain slices shows that the phosphatase is localized predominantly on postsynaptic densities (PSD) and dendritic microtubules (Wood et al., 1980). More recent studies have shown that the enzyme is found in chick brain and that its level increases during synaptogenesis (Tallant and Cheung, 1983). Also, the phosphatase is present in synaptic terminals of chick retina, where it is found in synaptoplasm, synaptic vesicles, synaptic membranes, and in subcellular fractions of synaptic plasma membranes and synaptic junctions (Cooper et al., 1985). Shields et al. (1985) have detected significant levels in cytosol and synaptosol of rat brain, but little if any in synaptic junctions or synaptic plasma membranes. Tallant and Cheung (1983) observed a considerable amount of phosphatase in a $100,000 \times g$ supernatant of rat brain. Nevertheless, a detailed analysis of the subcellular distribution of the enzyme in any tissue has not been reported.

We have chosen chick brain for the quantitative subcellular localization of calmodulin-dependent phosphatase because chicks show little intraspecies variability, are easy to care for, and are inexpensive. Moreover, the subcellular fractions from chick have been well characterized (Babitch et al., 1976; Anthony and Babitch, 1985).

\section{Materials and Methods}

Materials. $\mathrm{Na}^{125} \mathrm{I}(13-17 \mathrm{mCi} / \mu \mathrm{g})$ was purchased from Amersham. BioRad supplied the Enzymobead radioiodination reagent and SDS. Sigma supplied Triton X-100, phenylmethylsulfonyl fluoride (PMSF), dithiothreitol (DTT), leupeptin, aprotinin, polyethylene glycol, $n$-octylglucoside, sucrose, and BSA. Ficoll 400, Dextran T-500, and disposable Sephadex G-25 (PD-10) columns were obtained from Pharmacia. Auroprobe reagents for immunoblotting (GAR-G-BL), immunoelectron microscopy (GAR-G-LM), and a silver-enhancement kit were furnished by Janssen. New Zealand white rabbits were provided by a local supplier, newborn male Leghorn chicks by Stillwater Hatchery (Stillwater, OK), and bovine brains by Hernando Boneless Beef (Hernando, MS). Goat anti-rabbit immunoglobulin serum was a gift from Dr. William Walker, and rat oligodendrocytes were prepared by Dr. Yu-Yan Yeh, both of St. Jude Children's Research Hospital, Memphis, TN.

Iodination of calmodulin-dependent phosphatase. Calmodulin-dependent phosphatase was purified from bovine brain (Tallant et al., 1983) and stored in $50 \mathrm{~mm}$ Tris- $\mathrm{HCl}, \mathrm{pH} 7.0,0.5 \mathrm{~mm}$ DTT containing $60 \%$ 

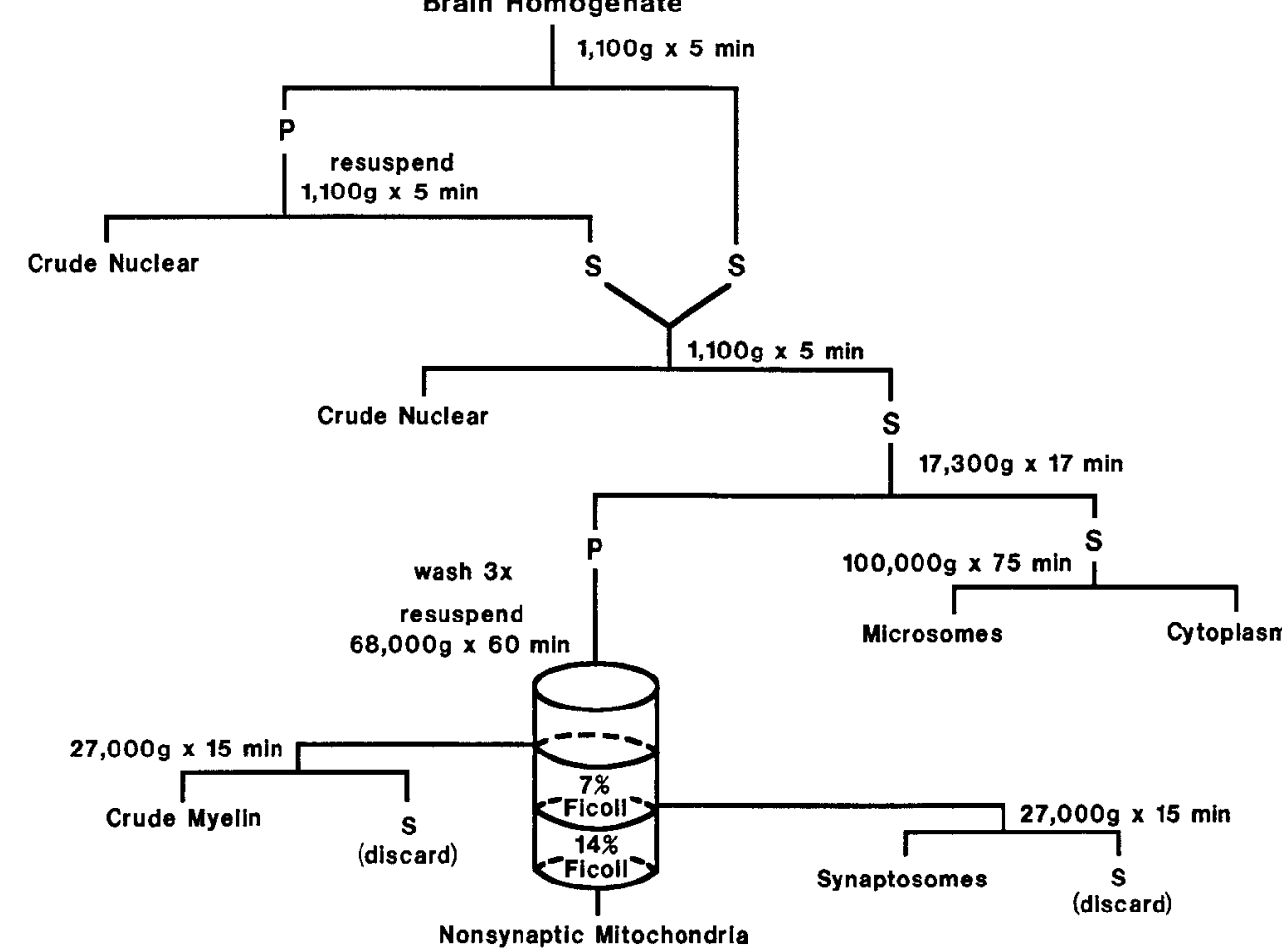

Figure 1. Diagrammatic scheme of the subcellular fractionation of chick forebrain homogenate.
Nonsynaptic Mitochondria

a one-step sucrose density gradient. The pellet represented synaptic mitochondria; all other materials were collected, mixed, and centrifuged for $14 \mathrm{hr}$ at $25,000 \times \mathrm{g}_{\mathrm{av}}$. The supernatant fluid represented synaptoplasm. The pellet was resuspended and centrifuged on a 5-step sucrose density gradient. The purest synaptic vesicles (SV) banded at the top of the $0.4 \mathrm{M}$ sucrose layer of the 5-step sucrose density gradient, while the purest presynaptic membranes (SPM) banded at the $0.8 / 0.95 \mathrm{~mm}$ sucrose interface (Babitch et al,, 1976). All steps were performed at $4^{\circ} \mathrm{C}$.

PSD and pre- and postsynaptic membranes with attached postsynaptic densities (SM) were isolated in the absence of EGTA according to Gurd et al. (1982), or Cohen et al. (1977).

Protein determination. Protein concentration was determined according to Lowry (1951), using BSA as the standard.

Electron microscopy and immunocytochemistry. Synaptosomes were pelleted and fixed in $0.1 \mathrm{M}$ sodium cacodylate, $\mathrm{pH} 7.3,0.2 \mathrm{M}$ sucrose, $0.5 \mathrm{mM} \mathrm{CaCl}_{2}, 2.6 \%$ glutaraldehyde, and $2 \%$ paraformaldehyde, rinsed in $0.1 \mathrm{M}$ sodium cacodylate, $\mathrm{pH} 7.3$, postfixed in $1 \%$ osmium tetraoxide in the cacodylate buffer, rinsed in 50\% ethanol, and then stained en bloc with $4 \%$ uranyl acetate in $50 \%$ ethanol. After dehydration with an ascending series of ethanol concentrations, the sample was embedded in Spurr. Thin sections were stained with lead citrate (Venable and Coggshall, 1965).

For cryosectioning, the synaptosome pellet was fixed overnight at $4^{\circ} \mathrm{C}$ in $0.1 \mathrm{M} \mathrm{K}_{2} \mathrm{HPO}_{4}$, $\mathrm{pH} 7.3,0.2 \mathrm{M}$ sucrose, $0.5 \mathrm{mM} \mathrm{CaCl}_{2}, 0.05 \%$ glutaraldehyde, and 3\% paraformaldehyde, and then immersed in $0.1 \mathrm{M}$ PBS containing $7 \%$ sucrose for $3 \mathrm{hr}$ at $4^{\circ} \mathrm{C}$. The pellet was transferred to 0.1 M 1-4-piperazine-diethanesulfonic acid (PIPES), pH 7.0, containing 2.3 M sucrose for $3 \mathrm{hr}$ at $4^{\circ} \mathrm{C}$, frozen by liquid nitrogen-cooled copper-lined pliers, and stored under liquid nitrogen.

Frozen sections $(100 \mathrm{~nm})$ were cut on a Sorvall FS 1000 cryosectioning system at $-100^{\circ} \mathrm{C}$ and placed on grids, which were inverted onto a plate of $2 \%$ gelatin and $0.75 \%$ agarose for $30 \mathrm{~min}$. Subsequent manipulations were done at $22^{\circ} \mathrm{C}$. The grids were floated up with $0.02 \mathrm{M}$ Tris- $\mathrm{HCl}, \mathrm{pH}$ $7.4,0.9 \% \mathrm{NaCl}$ (TBS) containing $0.01 \mathrm{M}$ glycine for $15 \mathrm{~min}$ and conditioned on $3 \%$ gelatin in TBS for $15 \mathrm{~min}$. Onc drop of phosphatase antiserum diluted $1: 100$ in TBS with $1 \%$ gelatin was allowed to interact with the cut sections on each grid for $60 \mathrm{~min}$. The grids were rinsed twice for $5 \mathrm{~min}$ with TBS containing $0.1 \%$ gelatin. Goat anti-rabbit gold-labeled immunoglobulin (GAR-G-LM) diluted 1:20 in TBS containing $0.1 \%$ gelatin was placed on each grid and allowed to interact with the primary antibody for $60 \mathrm{~min}$. Each grid was rinsed in TBS containing $0.1 \%$ gelatin twice for $5 \mathrm{~min}$, and finally in water. Sections 


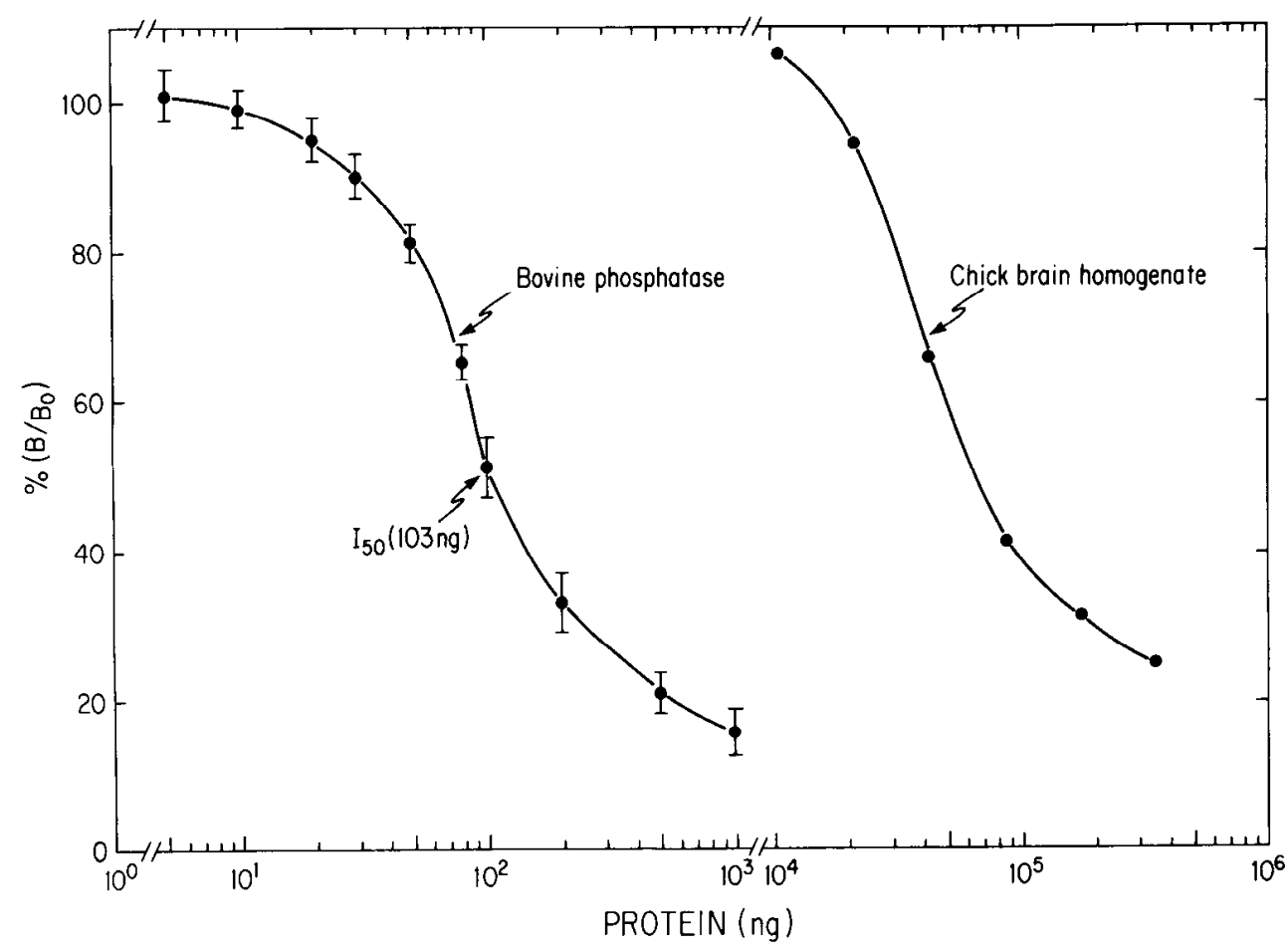

Figure 2. Radioimmunoassay of calmodulin-dependent phosphatasc. Binding is represented as $\%\left(B / B_{0}\right)$, where $B$ represents counts bound in the presence of increasing amounts of unlabeled antigen and $B_{0}$ represents counts bound in the absence of unlabeled antigen. For bovine brain phosphatase, the maximum $B_{0}$ varied depending upon the extent of iodination, but was usually about $30 \%$. These data represent the mean $\pm \mathrm{SD}$ from 10 different assays. The homogenate was prepared from chick forebrain. Other details are given under Materials and Methods. were stained in a $1: 1$ mixture of $2 \%$ phosphotungstic acid and $1.5 \%$ Tylose 300 for $10 \mathrm{~min}$, then rinsed quickly and embedded in $1.5 \%$ Tylose. Samples were screened using a Philips 301 electron microscope. Control grids had no first antibody.

Polyacrylamide gel electrophoresis and PAGE immunoblotting. Electrophoresis was performed as described by DeBlas et al. (1979). Protein samples were heated at $90^{\circ} \mathrm{C}$ for 2 min prior to electrophoresis, and a 20 -well slab gel was run at $7 \mathrm{~mA} / \mathrm{gel}$.

After electrophoresis, the gel was incubated in transfer buffer (192 mM glycine, $25 \mathrm{~mm}$ Tris- $\mathrm{HCl}, \mathrm{pH} 8.4$, containing $20 \%$ methanol) for $30 \mathrm{~min}$, and the proteins were transferred to a sheet of nitrocellulose at $100 \mathrm{~mA}$ for $2 \mathrm{hr}$ (Towbin et al., 1979). The nitrocellulose was either stained with amido black or used for immunoblotting as described by Janssen (Piscataway, NJ). Briefly, after electrophoretic transfer, unoccupied protein-binding sites were saturated by incubating the membrane in $20 \mathrm{~mm}$ Tris- $\mathrm{HCl}$, pH $8.2,0.9 \% \mathrm{NaCl}, 20 \mathrm{~mm} \mathrm{NaN}_{3}$, and 5\% BSA for $45 \mathrm{~min}$ at $37^{\circ} \mathrm{C}$. The membrane was then incubated in $2 \mathrm{ml}$ of 20 m $\mathrm{M}$ Tris- $\mathrm{HCl}, \mathrm{pH} 8.2,0.9 \% \mathrm{NaCl}, 1 \%$ normal goat serum, and $0.1 \%$ BSA containing $2 \mu \mathrm{l}$ of phosphatase antiserum for $2 \mathrm{hr}$ at $22^{\circ} \mathrm{C}$. The membrane was washed 3 times $(50 \mathrm{ml}, 5 \mathrm{~min} /$ wash $)$ in $20 \mathrm{~mm}$ Tris$\mathrm{HCl}, \mathrm{pH} 8.2,0.9 \% \mathrm{NaCl}$, and $0.1 \% \mathrm{BSA}$, and then incubated in $2 \mathrm{ml}$ of $20 \mathrm{~mm}$ Tris- $\mathrm{HCl}, \mathrm{pH} 8.2,0.9 \% \mathrm{NaCl}, 20 \mathrm{~mm} \mathrm{NaN}_{3}, 0.4 \%$ gelatin $(\mathrm{wt} / \mathrm{vol})$, and $0.1 \% \mathrm{BSA}$, containing a 1:100 dilution of gold-labeled goat anti-rabbit immunoglobulin (GAR-G-BL). The nitrocellulose was incubated overnight and washed twice in $20 \mathrm{~mm}$ Tris- $\mathrm{HCl}, \mathrm{pH} 8.2,0.9 \%$ $\mathrm{NaCl}$, and $0.1 \% \mathrm{BSA}$. The blot was then silver-enhanced using a kit from Janssen.

\section{Results}

\section{RIA of calmodulin-dependent phosphatase}

A detergent-based RIA developed for bovinc brain calmodulindependent phosphatase (Tallant et al., 1983) was used to measure the enzyme level in subcellular fractions isolated from chick forebrain. Because new antiserum was prepared for these studies, we first determined its cross-reactivity with chick brain phosphatase. Figure 2 shows a typical RIA in which unlabeled bovine brain phosphatase was added to compete with iodinated phosphatase for the antibody over a 500 -fold concentration range. The amount of unlabeled protein displacing $50 \%$ of the iodin- ated phosphatase was about $100 \mathrm{ng}$, and the limit of detection was about $10 \mathrm{ng}$. Figure 2 also shows that a chick forebrain homogenate effectively displaced the iodinated phosphatase. The titration curves for bovine brain phosphatase and chick brain homogenate appeared to be parallel, indicating that the antibody against bovine phosphatase cross-reacted with the chick enzyme. These data established the utility of the antiserum for the measurement of calmodulin-dependent phosphatase in chick brain. Other experiments indicated that this antiserum is specific: Of the many proteins present in a crude extract of chick forebrain, the antibody recognized only subunits A and B of the phosphatase; it did not recognize any of the other proteins in the crude extract (see Fig. 4). Moreover, another polyclonal antibody against bovine brain calmodulin-dependent phosphatase, raised similarly in a rabbit, was extensively characterized and found to recognize only subunits A and B (Wallace et al., 1980); calmodulin, though sharing extensive homology with subunit B, was not recognized.

\section{Distribution of phosphatase in subcellular fractions}

Table 1 presents phosphatase levels measured by the RIA in subcellular fractions isolated from chick forebrain (Babitch et al., 1976). The level of enzyme detected in the homogenate was $1.8 \pm 0.5 \mu \mathrm{g} / \mathrm{mg}$ of protein (mean $\pm \mathrm{SEM} ; n=4$ ). This value appeared to be higher than that observed previously for chick brain, but was within the range observed in other brain tissues (Tallant and Cheung, 1983; Shields et al., 1985). Only the cytoplasm and microsome fractions showed a higher level than that observed in the homogenate. Expressed per gram of tissue, the level of phosphatase was also highest in the cytoplasm and microsome fractions.

Although phosphatase was observed in the nuclear fraction, this fraction is usually heavily contaminated with cytoplasmic particles (McEwen and Zigmond, 1972) and was therefore further purified (see Materials and Methods). Examination of the 
Table 1. Levels of calmodulin-dependent phosphatase in various subcellular fractions from chick forebrain

\begin{tabular}{lrllc} 
& $\begin{array}{l}\text { Protein } \\
(\mathrm{mg} / \mathrm{gm} \text { of } \\
\text { tissue) }\end{array}$ & $\begin{array}{l}\text { Phosphatase } \\
(\mu \mathrm{g} / \mathrm{mg} \text { of } \\
\text { protein) }\end{array}$ & $\begin{array}{l}(\mu \mathrm{g} / \mathrm{gm} \text { of } \\
\text { tissue })\end{array}$ & $\begin{array}{l}\text { (\% Distribu- }^{a} \\
\left.\text { tion }^{a}\right)\end{array}$ \\
\hline Homogenate & $106.2 \pm 8.1$ & $1.8 \pm 0.5$ & $196.3 \pm 50$ & 100 \\
Cytoplasm & $18.7 \pm 1.9$ & $2.6 \pm 0.9$ & $46.1 \pm 12.6$ & $21.4 \pm 3.0$ \\
Microsome & $15.1 \pm 1.4$ & $2.1 \pm 0.6$ & $29.8 \pm 6.9$ & $15.7 \pm 1.5$ \\
Crude nuclear & $11.3 \pm 1.3$ & $0.8 \pm 0.3$ & $7.7 \pm 2.7$ & $3.8 \pm 0.3$ \\
Crude myelin & $10.0 \pm 1.0$ & $1.0^{b}$ & $9.5^{b}$ & $4.1^{b}$ \\
Synaptosome & $5.5 \pm 0.7$ & $1.2 \pm 0.4$ & $6.4 \pm 1.4$ & $3.6 \pm 0.8$ \\
Nonsynaptic mitochondria & $2.9 \pm 0.5$ & $0.2^{c}$ & $0.9^{c}$ & $0.4^{c}$
\end{tabular}

The various subcellular fractions were prepared from chick forebrain, as described in Materials and Methods. Phosphatas was measured using an antiserum against bovine brain phosphatase. These data represent the mean \pm SEM from 4 different preparations. Each determination was duplicated. The 3 washes of the crude synaptosomal pellet made prior to the Ficoll gradient accounted for $20 \%$ of the total phosphatase. Other washes in the fractionation account for $12 \%$ of the total phosphatase. Taking these values into account, the total phosphatase recovery was $81 \%$; the protein recovery was $93 \%$.

a Percentage distribution based on the $\mu \mathrm{g} / \mathrm{gm}$ levels of phosphatase.

${ }^{b}$ Phosphatase was detected in only 1 of 4 different preparations

c Phosphatase was detected in 2 of 4 different preparations.

purified nuclei by RIA did not reveal a detectable level of phosphatase.

To isolate myelin, synaptosomes, and mitochondria, a pellet consisting of a crude synaptosome fraction was washed 3 times and then separated on a Ficoll gradient (see Fig. 1). These washes, which reduce microsomal contamination in the crude synaptosome fraction from 50\% to less than $15 \%$ (Gurd et al., 1974) contained a significant level of phosphatase. Therefore, the level of phosphatase in the microsome fraction may have been underestimated.

A small amount of phosphatase was observed in one of the 4 myelin preparations summarized in Table 1 . To further examine whether the phosphatase was present in myelin, the crude myelin fraction was purified. Phosphatase was subsequently found to be below the level of detection. The absence of detectable phosphatase in the myelin fraction does not necessarily preclude its presence in oligodendrocytes, which produce myelin in the CNS. However, oligodendrocytes purified from rat brain did not show any detectable phosphatase.

The level of phosphatase in the synaptosome fraction was $6.4 \pm 1.4 \mu \mathrm{g} / \mathrm{gm}$ tissue and represented $4 \%$ of the total phosphatase in chick forebrain. Synaptosomes isolated by this procedure have very few postsynaptic membranes and densities attached and thus represent mostly resealed presynaptic nerve endings (see Fig. $3 a$ and Babitch et al., 1976).

Phosphatase was barely detected in the mitochondria fraction, suggesting that the trace amount may have resulted from contamination by other fractions.

\section{Distribution of phosphatase in synaptic subfractions}

Because of the presence of a considerable amount of phosphatase in the synaptosome, and its potential role in neurotransmitter release (Tallant and Cheung, 1986), this fraction was subfractionated further. Table 2 lists the distribution of the enzyme in

Table 2. Levels of calmodulin-dependent phosphatase in various synaptic subfractions

\begin{tabular}{|c|c|c|c|c|}
\hline \multirow[b]{2}{*}{ Fraction } & \multirow{2}{*}{$\begin{array}{l}\text { Protein } \\
\text { (mg/gm of } \\
\text { tissue) }\end{array}$} & \multicolumn{3}{|c|}{ Phosphatase } \\
\hline & & $\begin{array}{l}(\mu \mathrm{g} / \mathrm{mg} \text { of } \\
\text { protein) }\end{array}$ & $\begin{array}{l}(\mu \mathrm{g} / \mathrm{gm} \text { of } \\
\text { tissue })\end{array}$ & $\begin{array}{l}\text { (\% Distribu- } \\
\text { tion }^{a} \text { ) }\end{array}$ \\
\hline Synaptosome & $5.7 \pm 1.0$ & $1.1 \pm 0.1$ & $6.0 \pm 0.3$ & 100 \\
\hline Synaptoplasm & $1.9 \pm 0.3$ & $3.2 \pm 0.2$ & $6.3 \pm 0.8$ & $99.9 \pm 12$ \\
\hline Synaptic mitochondria & $1.6 \pm 0.2$ & ND & ND & ND \\
\hline Sample/0.4 м & $0.1 \pm 0.0$ & $0.2^{b}$ & $<0.1^{b}$ & $0.2^{b}$ \\
\hline $0.4 / 0.6 \mathrm{M}$ & $0.1 \pm 0.0$ & $0.3 \pm 0.0$ & $<0.1$ & $0.3 \pm 0.1$ \\
\hline $0.6 / 0.8 \mathrm{M}$ & $0.2 \pm 0.1$ & $0.2 \pm 0.0$ & $<0.1$ & $1.0 \pm 0.1$ \\
\hline $0.8 / 0.95 \mathrm{M}$ & $0.4 \pm 0.3$ & $0.3 \pm 0.0$ & $0.1 \pm 0.0$ & $2.0 \pm 0.8$ \\
\hline $0.95 / 1.1 \mathrm{~m}$ & $0.2 \pm 0.1$ & $0.3 \pm 0.0$ & $<0.1$ & $0.9 \pm 0.1$ \\
\hline Pellet & $0.2 \pm 0.0$ & $0.4^{b}$ & $<0.1^{b}$ & $1.5^{b}$ \\
\hline
\end{tabular}

The various synaptic subfractions were prepared from synaptosomes, as described in Materials and Methods. The data represent the mean \pm SEM of 5 separate determinations from 3 different preparations. Each determination was duplicated. The total protein recovery was $90 \%$ and the phosphatase recovery was usually $90-110 \%$. ND, not detected.

a Percentage distribution based on the $\mu \mathrm{g} / \mathrm{gm}$ levels of phosphatase.

${ }^{b}$ Values observed in only 1 of 5 different phosphatase determinations from 3 different synaptic subfractionation preparations. 
Table 3. Levels of calmodulin-dependent phosphatase in various subcellular fractions obtained from the isolation of PSD

\begin{tabular}{|c|c|c|c|c|}
\hline \multirow[b]{2}{*}{ Fraction } & \multirow{2}{*}{$\begin{array}{l}\text { Protein } \\
\text { (mg/gm of } \\
\text { tissue) }\end{array}$} & \multicolumn{3}{|c|}{ Phosphatase } \\
\hline & & $\begin{array}{l}(\mu \mathrm{g} / \mathrm{mg} \text { of } \\
\text { protein })\end{array}$ & $\begin{array}{l}\text { ( } \mu \mathrm{g} / \mathrm{gm} \text { of } \\
\text { tissue) }\end{array}$ & $\begin{array}{l}\text { (\% Distribu- } \\
\text { tion }^{a} \text { ) }\end{array}$ \\
\hline Homogenate & 101.6 & $2.5 \pm 0.1$ & 249.9 & 100 \\
\hline Supernatant 1 & 31.1 & $2.8 \pm 0.0$ & 88.6 & 35.4 \\
\hline Supernatant 2 & 16.8 & $4.4 \pm 0.2$ & 73.8 & 29.5 \\
\hline Crude nuclear & 20.7 & $1.2 \pm 0.1$ & 17.2 & 6.8 \\
\hline Crude mitochondria & 7.4 & $0.9 \pm 0.1$ & 6.4 & 2.5 \\
\hline Crude myelin & 0.8 & $0.6 \pm 0.0$ & 0.5 & 0.2 \\
\hline Synaptic membranes & 2.8 & $1.2 \pm 0.0$ & 3.4 & 1.4 \\
\hline PSD & 0.4 & $0.2 \pm 0.0$ & 0.1 & $<0.1$ \\
\hline
\end{tabular}

Washes not listed in this table account for $10 \%$ of the total phosphatase. Supernatant 1 represents a mixture of cytoplasmic and microsomal material. Supernatant 2 was obtained after lysis of crude synaptosomes. The data represent the mean and SD from 4 determinations. The protein recovery was $98 \%$, and the phosphatase recovery was $86 \%$. PSD, postsynaptic densities.

a Percentage distribution based on the $\mu \mathrm{g} / \mathrm{gm}$ levels of phosphatase.

these synaptic subfractions. The highest level of the enzyme was observed in synaptoplasm, where the enzyme represented $0.32 \%$ of the total synaptoplasmic protein. The relative concentration of phosphatase (in $\mu \mathrm{g} / \mathrm{mg}$ protein) in the synaptoplasm was nearly 3 times that in the synaptosome fraction and almost twice that in the homogenate (see Table 1). This relative concentration was slightly enriched over the cytosol (Table 1) and was higher than that of any other subcellular fraction or synaptic subfraction.

Phosphatase was not detccted in synaptic mitochondria, supporting the supposition that the enzyme is not intrinsic to the mitochondria (see also Table 1).

A trace level of phosphatase was detected in only one of several preparations of the fraction at the sample $/ 0.4 \mathrm{M}$ interface. This fraction is enriched with synaptic vesicles, and the lack of detectable phosphatase suggested that it was unlikely to be associated with synaptic vesicles.

Phosphatase levels were uniformly low in the synaptic subfractions isolated from the sucrose density-gradient interfaces of $0.4 / 0.6 \mathrm{M}, 0.6 / 0.8 \mathrm{M}, 0.8 / 0.95 \mathrm{M}$ (purest presynaptic membranes), and $0.95 / 1.1 \mathrm{M}$ sucrose. It is conceivable that these low levels represent contamination by synaptoplasm.

\section{Electron microscopy of isolated synaptosomes}

The present subcellular localization study suggests that, within the synaptosome, the phosphatase is localized exclusively in the synaptoplasm; therefore, we further investigated the synaptosomes by immunocytochemistry. Figure $3 a$ is a micrograph of a typical preparation of synaptosomes after fixation, embedding, and staining. They contain synaptic vesicles, occasional mitochondria, and few or no attached postsynaptic membranes. Extrasynaptosomal mitochondria, synaptic membranes, and myelin are essentially absent. Figure $3 b$ is a micrograph from the same preparation of synaptosomes that were lightly fixed, frozen, and cryosectioned prior to immunocytochemical staining for the phosphatase. The reaction product is not restricted to the synaptic plasma membrane, but is randomly distributed within the synaptosome, suggesting a synaptoplasmic localization. The morphology of each synaptosome is not as distinct as that in Figure $3 a$ because of the reduced contrast associated with the cryosectioning procedure, and it is not possible to ascertain if the phosphatase is associated with any particular cellular organelle. In the control sample, only the secondary goat antirabbit antibody was used, and no reaction product was observed (Fig. 3c). Again, the morphology is not distinct because of the cryosectioning technique. These results are consistent with the RIA data indicating that the phosphatase was present in the cytoplasm of nerve terminals.

\section{Measurement of phosphatase in postsynaptic densities}

Immunocytochemical data have revealed that phosphatase is predominantly associated with PSD and dendritic microtubules (Wood et al., 1980). The procedures used for the isolation of subcellular fractions and synaptic subfractions described in Tables 1 and 2 did not yield PSD. Table 3 lists the various subcellular fractions obtained according to a different procedure (Gurd et al., 1982) and their levels of phosphatase, as measured by the RIA. Although some of the subcellular fractions in Table 3 bear labels similar to those in Tables 1 and 2, they should not be directly compared. Supernatant 1 (a mixture of cytoplasmic and microsomal proteins) and supernatant 2 (a mixture of proteins obtained following lysis of a crude synaptosome fraction) contained the highest levels of phosphatase. The crude nuclear and mitochondrial fractions contained minor levels of the enzyme, probably because of cross-contamination, and the crude myelin fraction contained even lower levels. The total level of phosphatase in these 3 fractions was less than $10 \%$ of the homogenate. Synaptic membranes (pre- and postsynaptic membranes with attached PSD) represented $1.4 \%$ of the total phosphatase. Further subfractionation of the synaptic membranes to obtain PSD indicated that the PSD accounted for less than $0.1 \%$ of the total phosphatase. Examination of this fraction using electron microscopy confirmed the presence of PSD (data not shown).

The PSD in Table 3 was obtained by using phase partitioning with polyethylene glycol and Dextran T-500 in the presence of $n$-octylglucoside, which could dissociate the phosphatase from the PSD during isolation. Therefore, another preparation of PSD was isolated by a more conventional procedure (Cohen et al., 1977). The crude synaptosome fraction was homogenized with Triton $\mathrm{X}-100$, and the homogenate was centrifuged to obtain a 

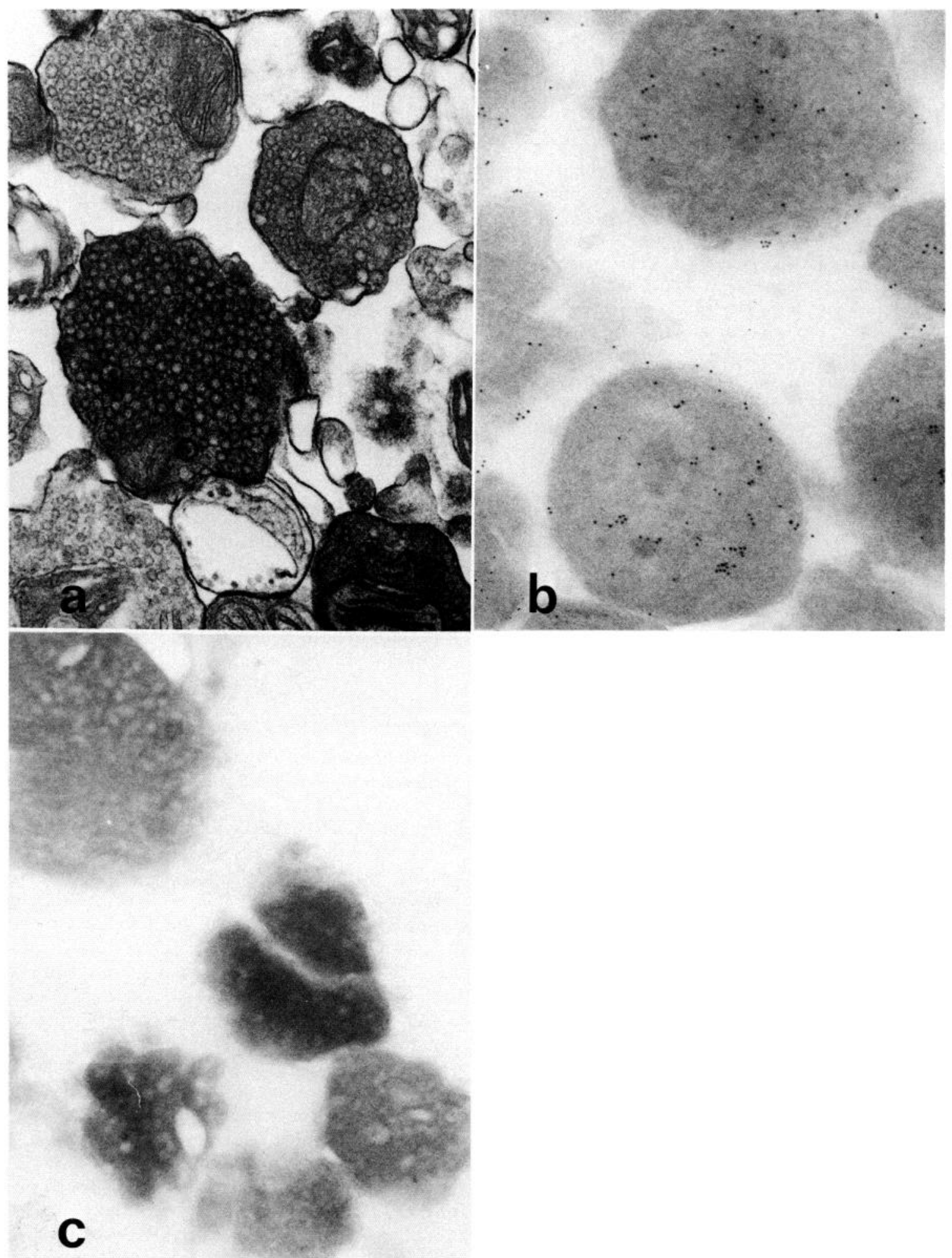

Figure 3. Electron micrographs of thin-sectioned synaptosomes isolated from chick forebrain. $a$, Spurr-embedded, unlabeled synaptosomes stained with lead citrate. $\times 49,500 . b$, Cryosection of synaptosomes first labeled with anti-calmodulin-dependent phosphatase and then with gold-labeled goat anti-rabbit immunoglobulin. $\times 49,400$. $c$, Cryosection of synaptosomes treated only with gold-labeled goat anti-rabbit immunoglobulin. $\times 49,400$.

Triton-insoluble pellet. The pellet was resuspended and then subfractionated on a sucrose density gradient to obtain PSD. Only $0.01 \%$ of the total phosphatase was observed in the synaptic membrane fraction, and phosphatase was below the level of detection in the PSD. Nevertheless, examination of this fraction using electron microscopy confirmed the presence of PSD (data not shown). Collectively, these results suggested that the PSD only contains a trace of the phosphatase. 


\section{PAGE immunoblots of PSD}

In addition to using the RIA, we also attempted to detect phosphatase in the PSD using an immunoblotting procedure. This procedure is more sensitive than the RIA, and, with silver enhancement, can detect as little as $0.1 \mathrm{ng}$ of protein (Moeremans et al., 1984). The procedure, however, is inherently not quantitative. Figure 4 shows the protein patterns on a nitrocellulose membrane after the proteins had been transferred from a polyacrylamide gel. The membrane was first incubated with rabbit anti-phosphatase serum and then with gold-labeled goat antirabbit immunoglobulin, and enhanced with silver. Figure 4, lane 1 contains $2 \mu \mathrm{g}$ of bovine brain phosphatase and shows 2 positive reaction bands at $60 \mathrm{kDa}$ (subunit $\mathrm{A}$ ) and $16 \mathrm{kDa}$ (subunit $\mathrm{B}$, which migrates as a broad band at $16 \mathrm{kDa}$ even though its $m_{r}$, according to amino acid sequence, is $19 \mathrm{kDa}$ ). Traces of a 45 and a $35 \mathrm{kDa}$ band-presumably proteolytic products of subunit A (Winkler et al., 1984)-were also observed. These results indicated that the antibody recognized both subunits $\mathrm{A}$ and B, in agreement with previous data (Cooper et al., 1985). Figure 4 , lane 2 contains $100 \mu \mathrm{g}$ of a chick forebrain homogenate and reveals a weak positive reaction at 60 and $35 \mathrm{kDa}$ and a strong reaction at $16 \mathrm{kDa}$. No other positive reactions were observed, indicating the specificity of the antisera. The weaker reaction at $60 \mathrm{kDa}$ may be due to a less effective transfer of subunit A, presumably because of a higher molecular weight or a species variability of subunit A or B. The possibility of species variability cannot be excluded, but would appear unlikely in view of the nearly perfectly parallel titration curves of bovine brain calmodulin-dependent phosphatase and a chick brain homogenate (see Fig. 1). Another possibility is that the antibody recognizes subunit B better than subunit A of chick brain phosphatase. Figure 4 , lane 3 contains $100 \mu \mathrm{g}$ of chick PSD proteins and reveals a faint reaction product at $60 \mathrm{kDa}$ and a strong reaction at $16 \mathrm{kDa}$. A control immunoblot, treated with nonimmune rabbit antisera and then with gold-labeled goat antirabbit immunoglobulin or with gold-labeled goat anti-rabbit immunoglobulin alone, showed no reaction product. Another control immmunoblot indicated that the antiserum did not crossreact with calmodulin (data not shown). Inherent in electrophoretic transfer is the limitation that the procedure is not quantitative, and low levels of phosphatase might not be detected. In spite of this limitation, these results are consistent with the notion that the phosphatase is present as a minor component in the PSD.

\section{Discussion}

Although calmodulin-dependent phosphatase has been found in many tissues and localized in a few, this report represents the first detailed quantitative localization of the enzyme in subcellular fractions isolated from any tissue. Inherent in any subcellular localization study are the limitations that the recovery of the enzyme is usually not quantitative and that the possibility of cross-contamination between fractions cannot be excluded. Thus, these results should be viewed with these limitations in mind.

We found that in chick brain the highest level of the enzyme occurred in the cytoplasm and microsomes. Further subcellular fractionation revealed that the synaptosome contained a considerable amount of the enzyme, which was localized exclusively to the synaptoplasm. A trace of phosphatase was detected in

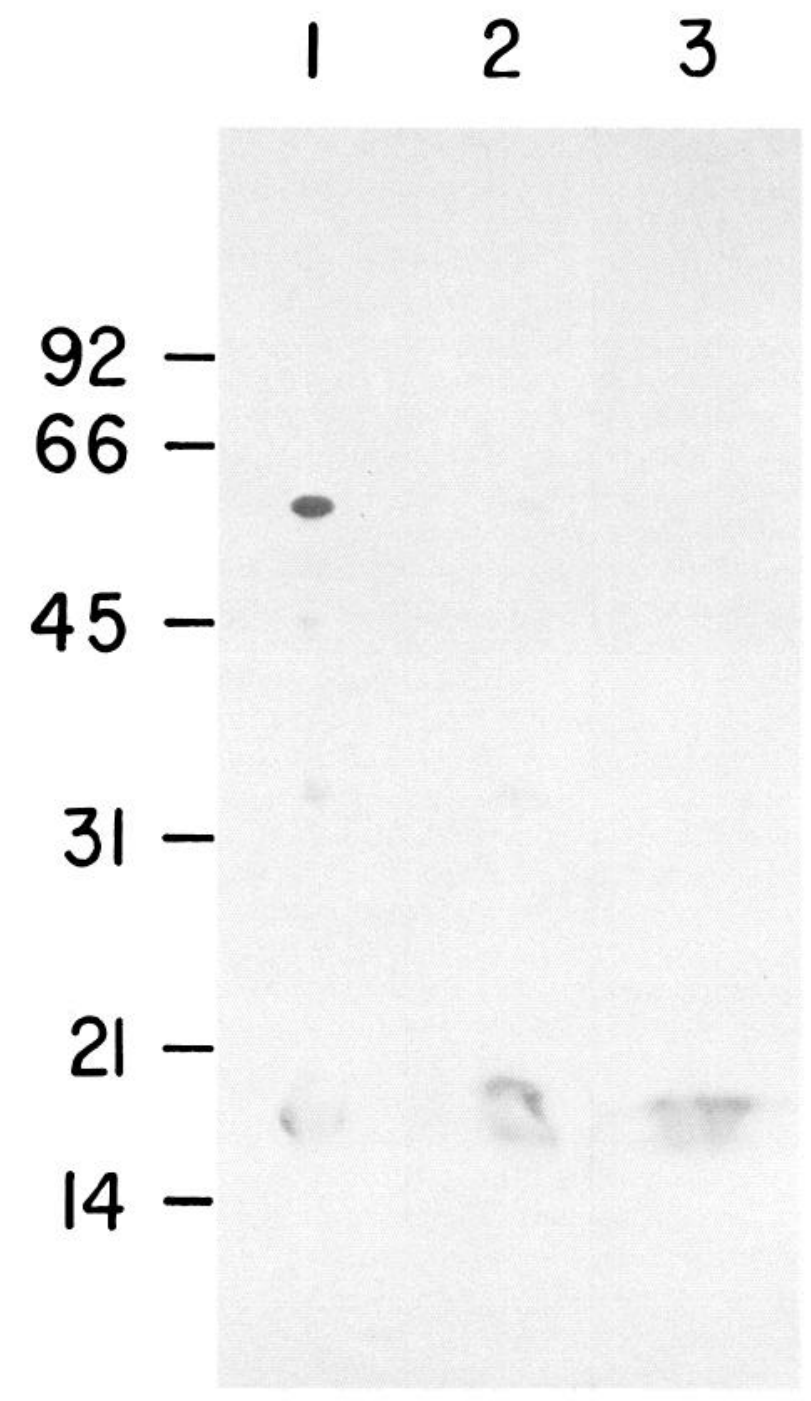

Figure 4. PAGE immunoblot of phosphatase and isolated PSD. A 12$18 \%$ linear gradient gel was run overnight at $7 \mathrm{~mA} / \mathrm{gel}$ and the proteins were transfered to a nitrocellulose membrane. The resulting blot was incubated with antibodies and silver-enhanced as described under Materials and Methods. Lane 1, $2 \mu \mathrm{g}$ of bovine brain phosphatase; lane 2, $100 \mu \mathrm{g}$ of chick forebrain homogenate; lane $3,100 \mu \mathrm{g}$ of chick PSD.

the PSD, and phosphatase was below the level of detection in mitochondria, synaptic vesicles, nuclei, and myelin.

Wood et al. (1980), Cooper et al. (1985), and Goto et al. (1986) have reported that the phosphatase is found only in neurons and not in any glial cells. We did not detect any phosphatase in chick brain myelin, nor did we detect it in brain nuclei. Kuret et al. (1986) also did not detect the enzyme activity in a rat liver nuclear lysate. The apparent lack of the phosphatase in myelin and nuclei implies that myelin basic protein and histone $\mathrm{H}_{1}, 2$ protein substrates frequently used for in vitro characterization of the enzyme, may not be physiological substrates.

Using immunocytochemistry, Cooper et al. (1985) have observed pre- and postsynaptic localization of the phosphatase. Our results extend this study and show that more phosphatase is present presynaptically in the synaptoplasm than postsynaptically in the PSD. In the synaptoplasm, the phosphatase comprises $0.32 \%$ of the synaptoplasmic proteins, whereas it 
accounts for a small amount in the synaptic membranes, and a trace level in the PSD.

The trace level of phosphatase found in the PSD appears to contrast with the immunocytochemical study of Wood et al. (1980), who found that phosphatase was predominantly localized at the PSD. Treatment of the brain tissue with fixative, a necessary step for immunocytochemical staining, could have cross-linked some soluble phosphatase to PSD; alternatively, some peroxidase reaction product could have precipitated at the PSD, giving rise to an apparently higher level of the enzyme. On the other hand, Somerville et al. (1984) have noted a high lability of PSD proteins, and, during our isolation procedure, some of the phosphatase might have dissociated from the PSD and not have been detected.

The finding that calmodulin-dependent phosphatase is concentrated in the cytosol of neurons and synaptosomes suggests that the enzyme may regulate protein dephosphorylation in nerve terminals. Synapsin is an in vitro substrate of the phosphatase and has been proposed as being involved in neurotransmitter release (Nestler and Greengard, 1984). Synapsin associated with synaptic vesicles is usually unphosphorylated, and when phosphorylated is dissociated from them (Schiebler et al., 1986), presumably facilitating the fusion of vesicles with the synaptic membrane and the release of neurotransmitter. Conceivably, phosphorylated synapsin would be accessible to the soluble synaptic phosphatase. DARPP-32 and G-substrate, which are cytosolic proteins dephosphorylated by the phosphatase in vitro (Nestler and Greengard, 1984), may likewise be potential in vivo substrates.

In summary, our results show that calmodulin-dependent phosphatase is primarily localized in the cytoplasm, microsomes, and synaptoplasm; these subcellular fractions may prove to be a useful source for the identification of physiological substrates.

\section{References}

Aitken, A., P. Cohen, S. Santikarn, D. H. Williams, A. G. Galder, A. Smith, and C. B. Klee (1982) Identification of the $\mathrm{NH}_{2}$-terminal blocking group of calcineurin B as myristic acid. FEBS Lett. 150:314318.

Aitken, A., C. B. Klee, and P. Cohen (1984) The structure of the B subunit of calcineurin. Eur. J. Biochem. 139: 663-671.

Anthony, F. A., and J. A. Babitch (1985) Calcium-binding proteins in whole brain and synaptic subfractions. Brain Res. 345: 124-131.

Anthony, F. A., D. L. Merat, and W. Y. Cheung (1986) A spectrofluorimetric assay of calmodulin-dependent protein phosphatase using 4-methylumbelliferyl phosphate. Anal. Biochem. 155: 103-107.

Babitch, J. A., T. B. Breithaupt, T.-C. Chiu, R. Garadi, and D. L. Helseth (1976) Preparation of chick brain synaptosomes and synaptosomal membranes. Biochim. Biophys. Acta 433: 75-89.

Babu, Y. S., J. S. Sack, T. J. Greenhough, C. E. Bugg, A. R. Means, and W. J. Cook (1985) Three-dimensional structure of calmodulin. Nature 315: 37-40.

Campbell, A. K. (1983) Intracellular Calcium, Wiley, New York.

Carr, S. A., K. Biemann, S. Shoji, D. C. Parmelee, and K. Titani (1982) $n$-Tetradecanoyl is the $\mathrm{NH}_{2}$-terminal blocking group of the catalytic subunit of cyclic AMP-dependent protein kinase from bovine cardiac muscle. Proc. Natl. Acad. Sci. USA 79: 6128-6131.

Chan, C. P., B. Gallis, D. K. Blumenthal, C. J. Pallen, J. H. Wang, and E. G. Krebs (1986) Characterization of the phosphotyrosyl protein phosphatase activity of calmodulin-dependent protein phosphatase. J. Biol. Chem. 261: 9890-9895.

Cheung, W. Y. (1980) Calmodulin plays a pivotal role in cellular regulation. Science 207: 19-27.

Cheung, W. Y. (1984) Biological functions of calmodulin. Harvey Lect. 79: 173-216.
Cohen, R. S., F. Blomberg, K. Berzins, and P. Siekevitz (1977) The structure of postsynaptic densities isolated from dog cerebral cortex. J. Cell Biol. 74: 181-203.

Cooper, N. G. F., B. J. McLaughlin, E. A. Tallant, and W. Y. Cheung (1985) Calmodulin-dependent protein phosphatase: Immunocytochemical localization in chick retina. J. Cell Biol. 101: 1212-1218.

DeBlas, A. L., W.-J. Wang, R. Sorensen, and H. R. Mahler (1979) Protein phosphorylation in synaptic membranes regulated by adenosine 3':5'-monophosphate: Regional and subcellular distribution of the endogenous substrates. J. Neurochem. 33: 647-659.

Goto, S., Y. Matsukado, Y. Mihara, N. Inoue, and E. Miyamoto (1986) Calcineurin as a neuronal marker of human brain tumors. Brain Res. 371: $237-243$.

Gurd, J. W., L. R. Jones, H. R. Mahler, and W. J. Moore (1974) Isolation and partial characterization of rat brain synaptic plasma membranes. J. Neurochem. 22: 281-290.

Gurd, J. W., P. Gordon-Weeks, and W. H. Evans (1982) Biochemical and morphological comparison of postsynaptic densities prepared from rat, hamster, and monkey brains by phase partitioning. J. Neurochem. 39: 1117-1124.

Kamps, M. P., J. E Buss, and B. M. Sefton (1985) Mutation of $\mathrm{NH}_{2-}$ terminal glycine of p60 $0^{\mathrm{src}}$ prevents both myristoylation and morphological transformation. Proc. Natl. Acad. Sci. USA 82: 4625-4628.

King, M. M., and C. Y. Huang (1984) The calmodulin-dependent activation and deactivation of the phosphoprotein phosphatase, calcineurin, and the effect of nucleotides, pyrophosphate, and divalent metal ions. J. Biol. Chem. 259: 8847-8856.

Klee, C. B., and T. C. Vanaman (1982) Calmodulin. Adv. Prot. Chem. 35: $213-321$.

Klee, C. B., T. H. Crouch, and M. H. Krinks (1979) Calcineurin: A calcium- and calmodulin-binding protein of the central nervous system. Proc. Natl. Acad. Sci. USA 76: 6270-6273.

Klumpp, S., A. L. Steiner, and J. E. Schultz (1983) Immunocytochemical localization of cyclic GMP, cGMP-dependent protein kinase, calmodulin, and calcineurin in Paramecium tetraurelia. Eur. J. Cell Bio. 32: 164-170.

Kretsinger, R. H. (1980) Structure and evolution of calcium-modulated proteins. CRC Crit. Rev. Biochem. 8: 119-174.

Kuret, J., H. Bell, and P. Cohen (1986) Identification of high levels of protein phosphatase-1 in rat liver nuclei. FEBS Lett. 203: 197202.

Li, H.-C. (1984) Activation of brain calcineurin phosphatase towards nonprotein phosphoesters by $\mathrm{Ca}^{2+}$, calmodulin, and $\mathrm{Mg}^{2+}$. J. Biol. Chem. 259: 8801-8807.

Lowry, O. H., N. J. Rosebrough, A. L. Farr, and R. J. Randall (1951) Protein measurement with the folin phenol reagent. J. Biol. Chem. 193: 265-275.

Marchildon, G. A., J. E. Casnellie, K. A. Walsh, and E. G. Krebs (1984) Covalently bound myristate in a lymphoma tyrosine protein kinase. Proc. Natl. Acad. Sci. USA 81: 7679-7682.

McEwen, B. S., and R. E. Zigmond (1972) Isolation of brain cell nuclei. Res. Methods Neurochem. 1: 139-161.

Merat, D. L., Z. Y. Hu, T. E. Carter, and W. Y. Cheung (1985) Bovine brain calmodulin-dependent protein phosphatase. J. Biol. Chem. 260: 11053-11059.

Moeremans, M., G. Daneels, A. Van Dijck, G. Langanger, and J. DeMey (1984) Sensitive visualization of antigen-antibody reactions in dot and blot immune overlay assays with immunogold and immunogold/ silver staining. J. Immunol. Methods 74: 353-360.

Nestler, E. J., and P. Greengard (1984) Protein phosphorylation in the Nervous Sysem, Wiley, New York.

Norton, W. T., and S. E. Poduslo (1973) Myelination in rat brain: Method of myelin isolation. J. Neurochem. 21: 749-757.

Pallen, C. J., and J. H. Wang (1983) Calmodulin-stimulated dephosphorylation of $p$-nitrophenyl phosphate and free phosphotyrosine by calcineurin. J. Biol. Chem. 258: 8550-8553.

Pallen, C. J., and J. H. Wang (1985) A multifunctional calmodulinstimulated phosphatase. Arch. Biochem. Biophys. 237: 281-291.

Pallen, C. J., K. A. Valentine, J. H. Wang, and M. D. Hollenberg (1985) Calcineurin-mediated dephosphorylation of the human placental membrane receptor for epidermal growth factor urogastrone. Biochemistry $24: 4727-4730$.

Schiebler, W., R. Jahn, J.-P. Doucet, J. Rothlern, and P. Greengard (1986) Characterization of synapsin I binding to small synaptic vesicles. J. Biol. Chem. 261: 8383-8390. 
Sefton, B. M., and T. Hunter (1984) Tyrosine protein kinases. Adv. Cyclic Nucleotide Res. 18: 195-225.

Sharma, R. K., R. Desai, D. M. Waisman, and J. H. Wang (1979) Purification and subunit structure of bovine brain modulator protein. J. Biol. Chem. 254: 4276-4282.

Shields, S. M., T. S. Ingbritsen, and P. T. Kelly (1985) Identification of protein phosphatase 1 in synaptic junctions: Dephosphorylation of endogenous calmodulin-dependent kinase II and synapse-enriched phosphoproteins. J. Ncurosci. 5: 3414-3422.

Somerville, R. A., P. A. Merz, and R. I. Carp (1984) The effects of detergents on the composition of postsynaptic densities. J. Neurochem. 43: 184-191.

Stewart, A. A., T. S. Ingebritsen, and P. Cohen (1983) The protein phosphatases involved in cellular regulation. 5. Purification and properties of a Ca ${ }^{2+} /$ calmodulin-dependent protein phosphatase (2B) from rabbit skeletal muscle. Eur. J. Biochem. 132: 289-295.

Tallant, E. A., and W. Y. Cheung (1983) Calmodulin-dependent protein phosphatase: A developmental study. Biochem. 22: 3630-3635.

Tallant, E. A., and W. Y. Cheung (1986) Calmodulin-dependent protein phosphatase. In Calcium and Cell Function, vol. 6, W.-Y. Cheung, ed., pp. 71-112, Academic, New York.

Tallant, E. A., and R. W. Wallace (1985) Characterization of a calmodulin-dependent protein phosphatase from human platelets. J. Biol. Chem. 260: 7744-7751.
Tallant, E. A., R. W. Wallace, and W. Y. Cheung (1983) Purification and radioimmunoassay of calmodulin-dependent protein phosphatase from bovine brain. Methods Enzymol. 102: 244-256.

Towbin, H., T. Staehelin, and J. Gordon (1979) Electrophoretic transfer of proteins from polyacrylamide gels to nitrocellulose sheets: Procedures and some applications. Proc. Natl. Acad. Sci. USA 76:43504354.

Van Eldik, L. J., J. G. Zendegui, D. R. Marshak, and D. M. Watterson (1982) Calcium-binding proteins and the molecular basis of calcium action. Int. Rev. Cytol. 77: 1-61.

Venable, J. H., and R. Coggshall (1965) A simplified lead citrate stain for use in electron microscopy. J. Cell Biol. 25: 407-408.

Wallace, R. W., E. A. Tallant, and W. Y. Cheung (1980) High levels of heat-labile calmodulin-binding protein $\left(\mathrm{CaM}-\mathrm{BP}_{80}\right)$ in bovine neostriatum. Biochemistry 19: 1831-1837.

Winkler, M. A., D. L. Merat, E. A. Tallant, S. Hawkins, and W. Y. Cheung (1984) Catalytic site of calmodulin-dependent protein phosphatase from bovine brain residues in subunit A. Proc. Natl. Acad. Sci. USA 81: 3054-3058.

Wood, J. G., R. W. Wallace, J. N. Whitaker, and W. Y. Cheung (1980) Immunocytochemical localization of calmodulin and a heat-labile calmodulin-binding protein $\left(\mathrm{CaM}-\mathrm{BP}_{80}\right)$ in basal ganglia of mouse brain. J. Cell Biol. 84: 66-76. 